\title{
Error Estimation in Glucose Testing Among Private and Public Medical Laboratories in Kalar District
}

\author{
Diyar Akbar Hasan
}

Department of Biology, College of Education, University of Garmian, Kalar, Kurdistan Region, Iraq

\begin{abstract}
Blood glucose estimation in medical labs is widely recommended by medical professionals in many clinical cases and may present with great opportunity for error that may impact the quality of test results and can occur at any stage of test processing which may be preanalytic, analytic, or postanaly tic.

In this study, twenty three public and private medical laboratories were assigned to measure glucose level in three standard solutions, labeled as: test A, testB and testC with concentrations of $75 \mathrm{mg} / \mathrm{dl}, 150 \mathrm{mg} / \mathrm{dl}$ and $250 \mathrm{mg} / \mathrm{dl}$, respectively. The standard error in glucose testing for the different solutions was assessed after receiving the data from the laboratories.It is observed that gender; years of experience, specialty, and scientific qualification of the lab technician had no observable effect on error and accuracy in glucose testing.

The results showed an increase in the standard error while increasing the concentration of standards as follow: $77.52 \pm 3.86 \mathrm{mg} / \mathrm{dl}$ for TestA, $148.61 \pm 7.72 \mathrm{mg} / \mathrm{dl}$ for TestB and $240.74 \pm 14.45 \mathrm{mg} / \mathrm{dl}$ for TestC. It is also demonstrated higher standard error in glucose testing with glucometers than spectrophotometric method. Using glucometer, the measured concentrations for TestA, TestB and TestC, were $75.14 \pm 11.25 \mathrm{mg} / \mathrm{dl}$, $159.29 \pm 24.22 \mathrm{mg} / \mathrm{dl}$ and $237.57 \pm 33.18 \mathrm{mg} / \mathrm{dl}$ respectively. Meanwhile the measure for TestA, TestB and TestC, using spectrophotometric method, were $78.56 \pm 3.0 \mathrm{mg} / \mathrm{dl}, 143.94 \pm 4.26 \mathrm{mg} / \mathrm{dl}$ and $242.13 \pm 15.71 \mathrm{mg} / \mathrm{dl}$ by respectively. In spite of a percentage of errors, The results concludes the superiority colorimetric enzy matic over point of care testing (glucometer) but further studies are recommended to assess error in glucose testing in both methods.
\end{abstract}

\section{Introduction}

Blood glucose testing in the hospital with point-of-care devices (glucometers) and other spectrophotometric devices is necessary and it is a routine test because blood glucose level, in addition to diabetes mellitus, elevated many pathological cases including endocrinopathies, genetic syndromes associated with diabetes, and infections ${ }^{(1)}$.

Glucose homeostasis becomes modified in these patients, thereby resulting in insulin resistance, hyperinsulinemia and consequent hyperglycemia. This set of conditions is named stress diabetes, and it is a physiological response that ensures glucose supply to non-insulin-dependent tissues such as hepatocytes, nerve cells and alveolar, endothelial and immune system cells.

Hyperglycemia is an independent predictor of adverse outcomes in cases of cardiovascular disease, neurological disorders, respiratory, liver and gastrointestinal disease, ma lignancy, sepsis and surgical patients $(2,3)$.

In medical lab, Glucose testing presents multiple opportunities for error. Any device can fail normal conditions. For glucose monitoring in the hospital, with thousands of operators, hundreds of devices, and dozens of locations involved, therefore, there is a great possibility of errors in the test results. Errors can be preanalytic, analytic, or postanalytic. Common sources of meter error include patient or methodology interferences, operator mistakes, environ mental exposure ، and device malfunction ${ }^{(4)}$. By understanding the source of the error and methods of prevention and correction, health care providers can help their patients use the systems more effectively ${ }^{(5)}$. 
It is essential to compare analytical methods for determination of blood glucose in clinical laboratory practice because it improves the quality of health care through accurate and reliable clinical decision making ${ }^{(6)}$.

Spectrophotometric method of plasma glucose estimation using glucose oxidase-peroxidase (GODPOD) is the gold standard method enzymatic GOD-POD method is specific for glucose, but it takes 10-15 minutes of time. Hence, it is not suitable for emergency cases ${ }^{(7)}$.

Using glucometers for glucose testing as point-of-care testing (POCT) or near patient testing is widely used at hospitals and homes both by medical professionals and patients. Their major advantage is faster turnaround times and use of minimal blood volumes ${ }^{(8)}$. They are used as a first line tool to get an idea about the current blood glucose levels ${ }^{(9)}$.

The aim of this study was to assess error and accuracy in glucose testing in some public hospital and private medical laboratories and also to compare colorimetric and point of care glucose (glucometer).

\section{Materials and methods}

\subsection{Study area}

This study was conducted in Kalar city, the center of Garmian administration from $1^{\text {st }}$ April to $1^{\text {st }}$ May, 2017.

\subsection{Included laboratories}

Twenty three public hospital and private medical laboratories were assigned to measure glucose level in the three standard solutions labeled as: test $\mathrm{A}$, test $\mathrm{B}$ and test $\mathrm{C}$ then the results returned to researcher on official paper belong to the lab and signed by the technician who performed the test.

The study also included a specially designed questionnaire form filled in meeting interview by the researcher and included the following information: Name of the technician, Age, gender, scientific qualification, specialty, Experience in years, Lab name, Type and manufacturing country of the analytical device.

\subsection{Preparation of standard glucose solutions}

In this study, a glucose solution of $1000 \mathrm{mg} / \mathrm{dl}$ was prepared as stock solution by adding $1000 \mathrm{mg}$ of pure glucose to $100 \mathrm{ml}$ distilled water then the formula $\mathrm{V} 1^{*} \mathrm{Cl}=\mathrm{V} 2 * \mathrm{C} 2$ adopted to prepare $100 \mathrm{ml}$ of three standard solutions with concentration $75 \mathrm{mg} / \mathrm{dl}, 150 \mathrm{mg} / \mathrm{dl}$ and $250 \mathrm{mg} / \mathrm{dl}$, which were named test $\mathrm{A}$, testB and testC respectively ${ }^{(10)}$. Finally, aliquots of eppindorff tubes of $0.5 \mathrm{ml}$ size were made from the three standards to be tested for glucose level by the 23 private and public laboratories by the use of both glucometer and spectrophotometric enzymatic methods. .

\subsection{Statistical analysis}

The data of the current study were entered into a Microsoft Excel Spreadsheet 2013 software for statistical analysis using descriptive statistic in which the data were expressed as mean, standard error of mean (Mean \pm S.E.M).

\section{Results}

\subsection{Laboratory technician according to gender}

In the current study, the gender-dependent distribution of Laboratory technician was $86.96 \%$ for males and 13.04\% for females (Table 1 and Fig.1).

Table 1: Laboratory technician according to sex

\begin{tabular}{|l|l|l|l|}
\hline & Male & Female & Total \\
\hline No. & 20 & 3 & 23 \\
\hline$\%$ & $86.96 \%$ & $13.04 \%$ & $100 \%$ \\
\hline
\end{tabular}




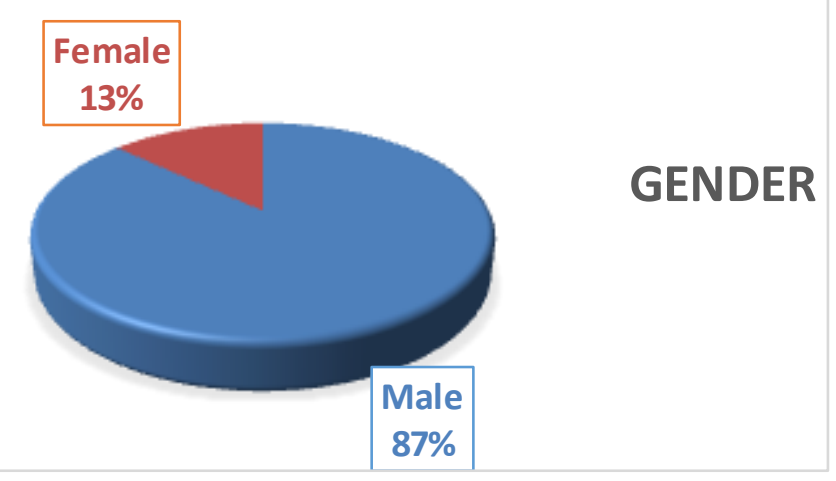

Figure 1: Laboratory technician according to gender

\subsection{Laboratory technician according to specialty}

In the current study, the specialty-dependent distribution of Laboratory technician was $22 \%$ for chemistry, $61 \%$ for medical lab techniques, $13 \%$ for biology, and $4 \%$ for microbiology (Table 2 and Fig. 2).

Table 2: Laboratory technician according to specialty

\begin{tabular}{|l|l|l|l|l|c|}
\hline & & & & & Total \\
\hline No. & chemistry & Medical lab technique & biology & microbiology & \\
\hline$\%$ & 5 & 14 & 3 & 1 & 23 \\
\hline
\end{tabular}

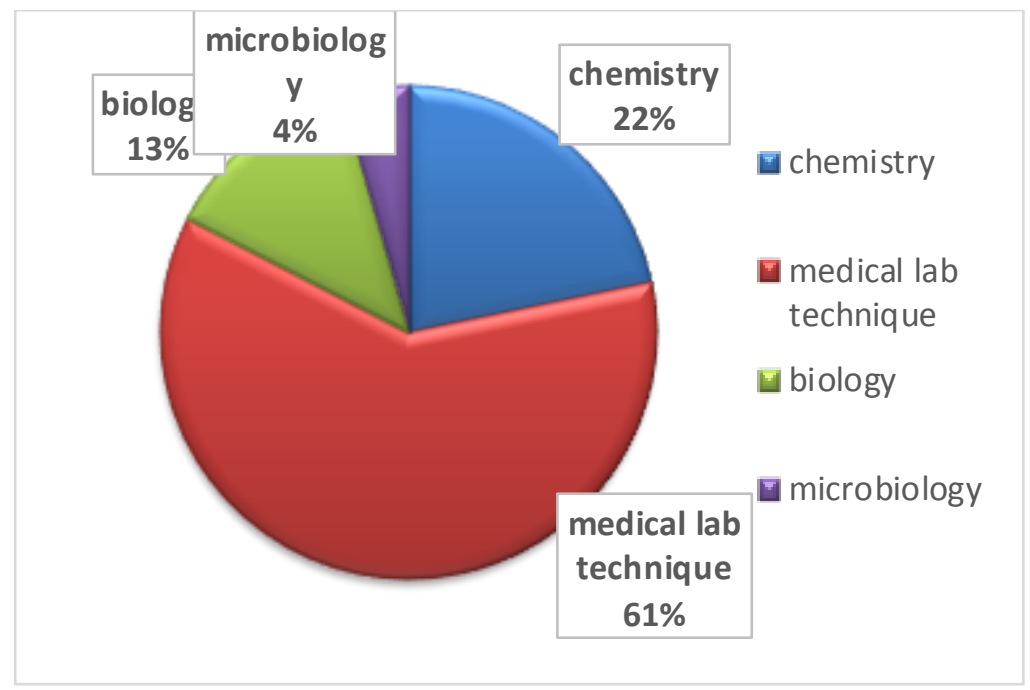

Figure 2: Laboratory technician according to specialty

\subsection{Biochemical analysis}

The result of current of study demonstrated increase in the standard error with increase in the concentration of standards as follow: $77.52 \pm 3.86 \mathrm{mg} / \mathrm{dl}$ for TestA, $148.61 \pm 7.72 \mathrm{mg} / \mathrm{dl}$ for TestB and $240.74 \pm 14.45 \mathrm{mg} / \mathrm{dl}$ for TestC (Table 3 and Fig. 3). 
Table 3: Lab estimation of standard concentrations in general

\begin{tabular}{|l|l|l|}
\hline standards & mean & Standard error \\
\hline TestA & 77.52 & \pm 3.86 \\
\hline TestB & 148.61 & \pm 7.72 \\
\hline TestC & 240.74 & \pm 14.45 \\
\hline
\end{tabular}

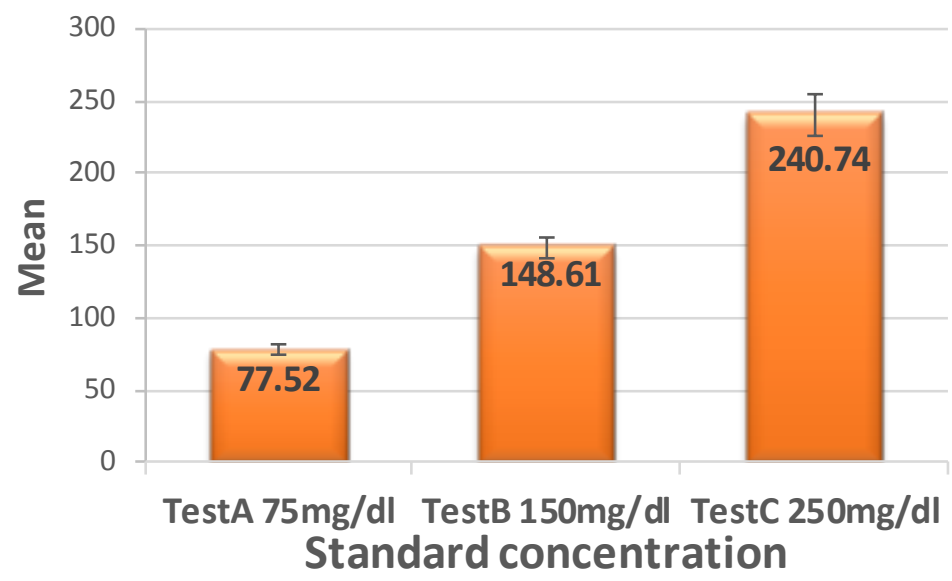

Figure 3: Lab estimation of standard concentrations in general

The result of current of study demonstrated higher standard error in the concentration of standards with glucometers than spectrophotometric methods as follow: $75.14 \pm 11.25 \mathrm{mg} / \mathrm{dl}$ for TestA, $159.29 \pm 24.22 \mathrm{mg} / \mathrm{dl}$ for TestB and $237.57 \pm 33.18 \mathrm{mg} / \mathrm{dl}$ for TestC by glucometer and $78.56 \pm 3.0 \mathrm{mg} / \mathrm{dl}$ for TestA, $143.94 \pm 4.26$ $\mathrm{mg} / \mathrm{dl}$ for TestB and $242.13 \pm 15.71 \mathrm{mg} / \mathrm{dl}$ for TestC by spectrophotometric method (Table 4 and Fig. 4).

Table 4: Lab estimation of standard concentrations with and without glucometers

\begin{tabular}{|l|l|l|l|l|}
\hline \multirow{2}{*}{$\begin{array}{c}\text { Method } \\
\text { standards }\end{array}$} & Colorimetry & glucometers & \\
\cline { 2 - 5 } & mean & Standard error & mean & Standard error \\
\hline Test $A$ & 78.56 & \pm 3.0 & 75.14 & \pm 11.25 \\
\hline Test $B$ & 143.94 & \pm 4.26 & 159.29 & \pm 24.22 \\
\hline Test $C$ & 242.13 & \pm 15.71 & 237.57 & \pm 33.18 \\
\hline
\end{tabular}

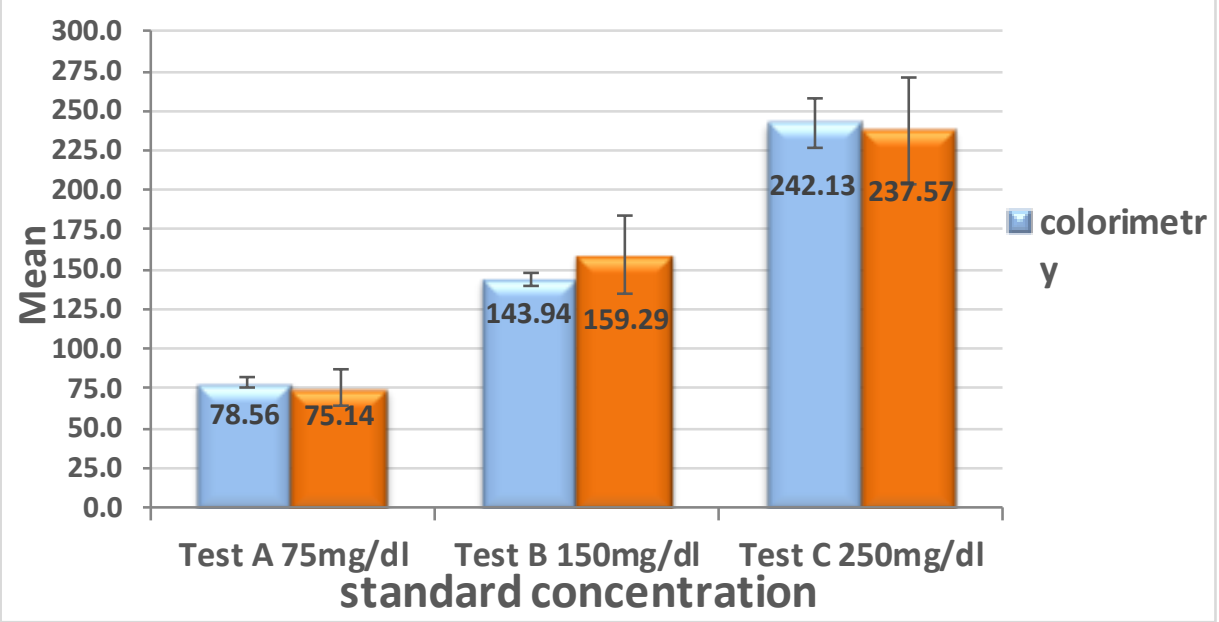

Figure 4: Lab estimation of standard concentrations with and without glucometers 
The result of current of study demonstrated non observable association between years of lab technician experience and standard error in the concentration of standards except for the TestC as follow: 68.0 \pm 4.85 $\mathrm{mg} / \mathrm{dl}$ for TestA, $137.9 \pm 5.66 \mathrm{mg} / \mathrm{dl}$ for TestB and $241.7 \pm 35.73$ for TestC by <4 years of lab work experience and $81.7 \pm 4.84 \mathrm{mg} / \mathrm{dl}$ for TestA, $153.3 \pm 10.73 \mathrm{mg} / \mathrm{dl}$ for TestB and $240.3 \pm 14.72 \mathrm{mg} / \mathrm{dl}$ for TestC by $\geq 4$ years of lab work experience (Table 5 and Fig. 5).

Table 5: Lab estimation of standard concentration in relation to years of experience

\begin{tabular}{|l|l|l|l|l|}
\hline $\begin{array}{c}\text { Years of experience } \\
\text { standards }\end{array}$ & $<4$ years & $\geq 4$ years & Standard error \\
\cline { 2 - 5 } & mean & Standard error & mean & \pm 4.84 \\
\hline Test A & 68.0 & \pm 4.85 & 81.7 & \pm 10.73 \\
\hline Test B & 137.9 & \pm 5.66 & 153.3 & \pm 14.72 \\
\hline Test C & 241.7 & \pm 35.73 & 240.3 & \\
\hline
\end{tabular}

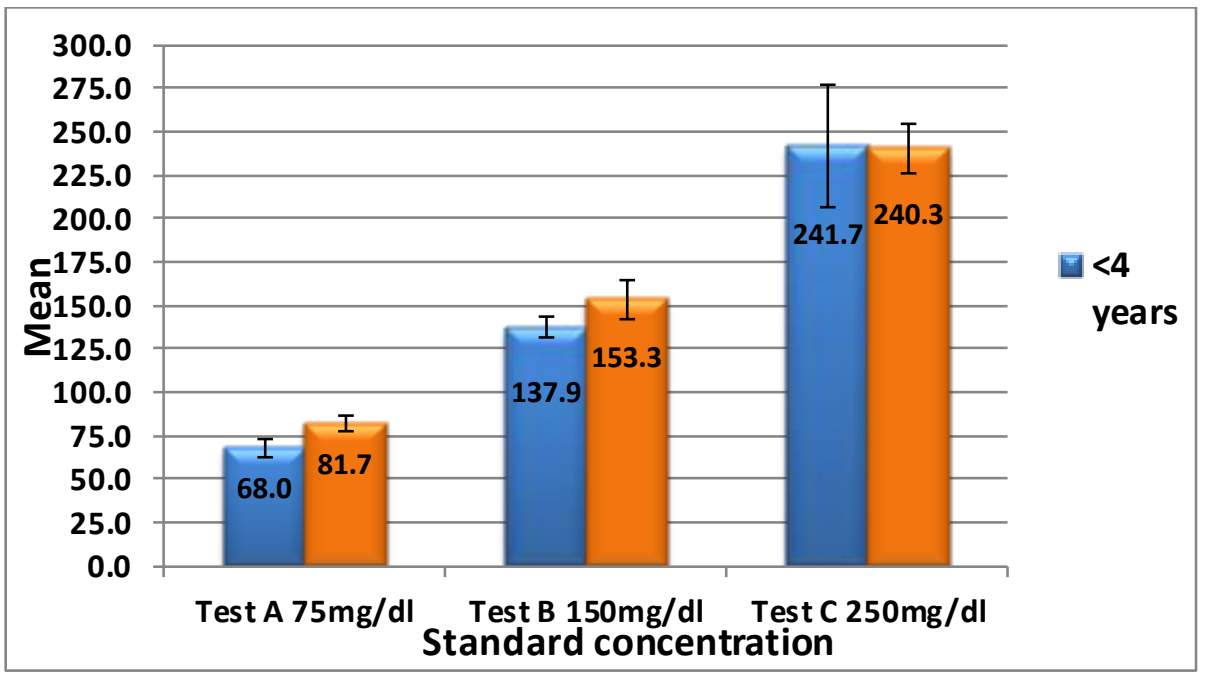

Figure 5: Lab estimation of standard concentration in relation to years of experience

\section{Discussion}

The result of current study goes with previous studies in term of erroneous result in glucose estimation which state that There are a number of potential risks of error with glucose estimation in the hospital and private laboratories and this may be attributed to patient، environ mental, device, and operator sources ${ }^{(11,12)}$ In The current study showed that lab estimation of the three glucose standards by private and public medical laboratories had some percentages of error in glucose measurement without regard to the device used. Measurement of the glucose standard of highest concentration (TestC $250 \mathrm{mg} / \mathrm{dl}$ ) showed the highest standard error other glucose standards and this can be explained by that absorbance of as solution may adhere to the Beer's law re lationship between light absorbance and concentration only over a certain range of concentrations, beyond which there may be a curvilinear relationship ${ }^{(13)}$. Measurement of the three standards was done by both glucometers and spectrophotometric method (glucose oxidase method) by the mentioned laboratories and the results showed that standard errors with glucometers were higher than those with spectrophotometric methods. This issue is also addressed by Khan et al., 2006 and Baig et al., 2007 $(14,15)$. Similarly, these authors have also asked the question about the reliability of glucometers. The reasons for the difference of glucose concentrations observed in glucometer are plentiful. Glucometer and its strips ought to be stored at optimal temperature; deviation from such affect glucose results adversely. Glucometer use enzymes which are liable to fluctuations in atmospheric temperature ${ }^{(7)}$. Other reasons include operational factors and faulty blood application ${ }^{(16,17)}$ the most common reasons are applying insufficient sample to the strip, expired strips, strips exposed to excess moisture or humidity, improper code, dirty meters, improper cleaning of the testing site and hemolysed sample. 


\section{Conclusions}

Higher standard errors in glucose testing with glucometer as compared to spectrophotometric method suggest that colorimetric enzymatic estimation of blood glucose remains gold standard method despite higher operational time and cost burden but this does not mean we recommend glucometer. In this study only glucose testing is use to assess error made medical laboratories by using different standard glucose solutions, therefore we suggest a further detailed study by involving different biochemical tests in addition glucose testing for estimation of errors.

\section{References}

[1] Crook, M.A. (2012) "Clinical Biochemistry and Metabolic Medicine", Eighth Edition. CRC Press.

[2] Vanhorebeek, I., Langouche, L., and Van den Berghe G. (2007) "Tight blood glucose control with insulin in the ICU: facts and controversies", Chest. 132(1):268-78.

[3] Mebis L, Gunst J, Langouche L, Vanhorebeek I, Van den Berghe, G. (2007) "Indication and practical use of intensive insulin therapy in the critically ill", Curr Opin Crit Care.13(4):392-8.

[4] Nichols, J.H. ( 2011) "Blood glucose testing in the hospital: error sources and risk management. Journal of diabetes science and technology, 5(1), pp.173-177.

[5] Ginsberg, B. H. (2009) "Factors Affecting Blood Glucose Monitoring: Sources of Errors in Measurement", J Diabetes Sci Technol, 3(4):903-913

[6] Boren, S.A. and W. L. Clarke, (2010) "analytical and clinical performance of blood glucose monitors", J Diabetes Sci Technol 2010;4(1):84-97

[7] Burtis, C. A., Ashwood, E. R. and Bruns, D. E, (2006) "Tietz textbook of clinical chemistry and molecular diagnostics". 4th ed. St Louis MissouriUSA: Elsevier Saunders.

[8] Sharma, S. P., Anjanker, A.P. and Kale A. (2017) "Comparison of glucose levels using glucometer and GOD-POD MethoD", Int J Clin Biochem and Research, 4(1):6-10.

[9] Koschinsky, T., Jungheim, K. and Heinemann, L. (2003) "Glucose sensors and the alternate site testing-like phenomenon: relationship between rapid blood glucose changes and glucose sensor signals", Diabetes Technol Ther, 5:829-842.

[10] Denniston, K. J., Topping, J. J., Quirk Dorr, D. R. and Caret R. L.(2017). General, organic, and biochemistry, $9^{\text {th }}$ ed. Published by McGraw-Hill Education, 2 Penn Plaza, New York.

[11] Klonoff, D. C. and Perz, J. F.( 2010) "Assisted monitoring of blood glucose: special safety needs for a new paradigm in testing glucose". J Diabetes Sci Technol. 4(5): 1027-31 .

[12] Ginsberg, B. H. (2010) "We need tighter regulatory standards for blood glucose monitoring, but they should be for accuracy disclosure", J Diabetes Sci Technol. 4(5):1265-8.

[13] Burtis C.A., Ashwood, E.R. and Bruns, D.E. (2012). "Tietz textbook of clinical chemistry and molecular diagnostics". 4th ed. St Louis MissouriUSA: Elsevier Saunders.

[14] Khan, A.I., Vasquez, Y., Gray, J., W ians, F and Kroll, M. (2006) "The variability of results between point-of-care testing glucose meters and the central laboratory analyzer. Arch Pathol Lab Med, 130(10):1527-32.

[15] Baig, A., Siddiqui, I., Jabbar, A., Azam, SI., Sabir, S., Alam S, et al.(2007) Comparison between bed side testing of blood glucose by glucometer vs. centralized testing in a tertiary care hospital. J Ayub Med Coll Abbottabad, 19(1):25-9.

[16] Bergenstal, M. D. and Richard, M. (2008) "Evaluating the accuracy of modern glucose meters", Insulin.;3(1):5-14.

[17] Johnson, R. N. and Baker, J. R.(2001) "Error detection and measurement in glucose monitors", Int J Clin Chem:307(1-2):61-7. 